\title{
Hurdles Faced in Getting a Clinical Biochemistry Laboratory Accredited by NABL in Government Setup: Our Experience
}

\author{
Kiran Dahiya ${ }^{1}$, Veena S Ghalaut ${ }^{2}$, Monica Verma ${ }^{3}$, Asha Kumari ${ }^{4}$, Deepika Dalal ${ }^{5}$
}

\begin{abstract}
Diagnostic care is the heart of the healthcare management system. Clinical laboratories that are accredited by National Accreditation Board for Testing and Calibration Laboratories (NABL) get worldwide acceptance. Accreditation is an attempt to encourage diagnostic laboratories performing basic tests to adopt quality practices, thus improving healthcare system at grass root level in the country. A large number of laboratories are now accredited, but majority of them are in private sector. Very few clinical laboratories associated with government organization participate and are able to achieve accreditation by NABL. Fortunately, our laboratory is one of them. With the experience gained during the process of getting NABL accreditation, we feel competent enough to comment upon and summarize the areas that may present difficulty in the process. We hope that most of the laboratory personnel working in the government organization will identify with our experience and get prepared as well as motivated to get their laboratory accredited by NABL.

Keywords: Biochemistry, Clinical laboratory, Government organization, Hurdles, National Accreditation Board for Testing and Calibration Laboratories.

Indian Journal of Medical Biochemistry (2020): 10.5005/jp-journals-10054-0136
\end{abstract}

\section{INTRODUCTION}

Accreditation of healthcare systems is increasingly seen as an approach to ensure good health standards and practices in both private and public organizations for better patient care. ${ }^{1}$ Accreditation is a procedure by which a third party gives formal recognition, authorization, and registration that a body (laboratory) or person (signatory authority) is capable, competent, and credible to carry out specific tasks (scope). ${ }^{2}$

National Accreditation Board for Testing and Calibration Laboratories (NABL), New Delhi, is a constituent board of Quality Council of India (QCI). It is a society registered under Societies Registration Act, 1860, and is an autonomous body under the aegis of Department of Science and Technology. The laboratory accreditation services are provided in accordance with ISO/IEC 17025 "General Requirements for the Competence of Testing and Calibration Laboratories" and ISO 15189 "Medical laboratoriesRequirements for Quality and Competence". ${ }^{3}$ It may be considered a philosophy of principles and a voluntary process including a wide array of quality tasks beyond just quality assurance and quality control. The advantages of accreditation include that laboratory reports are accepted internationally implying the concept "once tested, accepted everywhere," increasing the confidence of users (clinicians and patients) and service providers as well as boosting the reputation of the laboratory as well as the institute. ${ }^{4}$

As per the latest data available, of 867 laboratories, approximately 85 (9.8\%) accredited by NABL as per ISO 15189:2012 standard all over India are in government organizations. In the state of Haryana, there are only 2 such laboratories accredited by NABL till date. ${ }^{5}$ This signifies how horrendous a task it may seem for a clinical laboratory associated with a government organization. But nothing is impossible if you set your mind to it. Ours is a postgraduate institute with an indoor facility of more than 1,700 beds and an annual number of more than 15 lakhs for patients visiting outdoor facility and nearly 1 lakh for admissions. So, the workload on the Clinical Biochemistry Laboratory (CBL) is also understandably
1,3,5 Department of Biochemistry, Pandit Bhagwat Dayal Sharma Post Graduate Institute of Medical Sciences, Rohtak, Haryana, India

${ }^{2}$ Department of Biochemistry, SGT Medical College Hospital and Research Institute, Gurugram, Haryana, India

${ }^{4}$ Department of Biochemistry, SHKM Government Medical College, Mewat, Haryana, India

Corresponding Author: Kiran Dahiya, Department of Biochemistry, Pandit Bhagwat Dayal Sharma Post Graduate Institute of Medical Sciences, Rohtak, Haryana, India, Phone: +91 9896111985, e-mail: kirandahiya_2002@yahoo.com

How to cite this article: Dahiya K, Ghalaut VS, Verma M, et al. Hurdles Faced in Getting a Clinical Biochemistry Laboratory Accredited by NABL in Government Setup: Our Experience. Indian J Med Biochem 2020;24(1):1-3.

Source of support: Nil

Conflict of interest: None

huge. Our laboratory got NABL accreditation in the year 2017 with the earnest efforts of the whole staff. Dedicated, sincere, and enthusiastic manpower is the first and foremost requirement for any organization to be recognized. Fortunately, there was no dearth of such workforce in CBL which was eager to learn and modulate itself according to assigned job description. Here, we present a brief account of major hurdles faced by us during this journey. We feel that these are the common challenges faced by any laboratory undergoing this accreditation, but those in a government setup will be able to relate more to our experience.

\section{Chief Hurdles in NABl Accreditation of a Laboratory in Government Setup}

\section{Financial Assistance}

Any modification or improvement in the infrastructure or working of the system involves financial bearings. To comply with NABL 
document 112, you need to introduce changes both in the management and in the technical areas, which might be mundane to very significant proportions, and each one requires financial assistance. It pertains mainly but not solely to the accounts section of the institute and requires a stringent procedure involving huge paperwork and calls for continual monitoring. Because of the complexity involved, the whole procedure becomes quite long and gives you moments of helplessness interspersed with uncertainty. No government organization can be an exception to this, although the complexity of procedure may vary but in a private setting, it might be comparatively easier.

\section{Purchase Process}

To make the system fault proof to get through the assessment by the NABL team, you cannot afford to run out of small, daily use items such as Eppendorf tubes, organizers to keep aliquots, aluminum foil to store the samples, hand sanitizers, etc., which might not be available in hospital supply in routine and need to be purchased at departmental level. This, again, requires a long process of sending demand with specifications, getting it approved, and then to apply for the advance sanction or reimbursement of actual invoice or bills followed by the adjustment of the sanctioned amount. Each step takes time and sometimes gets returned in original with objections. So, the whole process is tedious and requires good amount of patience. Any person associated with a government organization will agree to it and will be able to identify with this fact.

\section{Support and Cooperation of the Administration}

Administrative support is also solicited at many steps. It may be to hold management review meetings, to give instructions to the hospital staff, to get the things done from purchase and account sections, to deploy extra staff wherever needed, or to utilize the institutional resources to fulfill the requirements as per NABL standard. The expenditure incurred during each inspection, be it internal audit, preassessment, final assessment, or on-site surveillance visit, needs to be approved by administration of the institute. An understanding, enthusiastic, and cooperative administration is a boon that can make the whole process smooth and easier. We still remember the efforts we had to put to procure a kit of Anti-HBs titer to check the vaccination status of the laboratory staff, as it is not done as a routine test in the institute.

\section{Sample Collection Area}

The outcome of quality of the laboratory work is significantly affected by the quality services at the point of sample collection. The central sample collection facility for the outdoor patients is not under direct supervision of Biochemistry Department but is looked after collectively by the administrative staff designated for the outdoor patient department (OPD). It was really a herculean task to manage and train the technical staff posted there which was already feeling overworked. They were doing their job properly but required to learn about safe and uniform practice of sample collection as per criteria laid down in NABL 112. It was achieved by conducting regular training classes followed by post-training evaluations that were scheduled keeping their convenience in mind and causing minimal disturbance to the facility. The infrastructure also required to be modified including expansion of the sample collection cabins, arrangement of curtains, or painting the glass partition opaque for privacy of patients, making different directories and work instructions available at the work area and revising labeling process to facilitate traceability both horizontally and vertically. Each step needed proper recording and documentation to minimize preanalytical nonconformities. So, lots of time and energy were expended to streamline this area, and things got a bit easier by implementation of hospital information system although it is yet to become fully operational.

\section{Recurring Processes for Upkeep of the Equipment}

This includes periodic calibration of each and every instrument used in the laboratory, either as small as a thermometer or big ones such as auto-analyzers. Calibration frequency is 6 months for some and annual for the others. It is carried out in the months of March and September each year for our laboratory. The whole process is tedious and involves sending demand, requesting invoice and quotations, getting approval, preparing comparative recommendations, getting the calibration carried out, and getting the bill remitted. Each step is prone to some or the other objection from the concerned section of the office, making the process of getting the instruments calibrated before due date a challenge every time. The effort is to keep the downtime of all the equipment to the minimum by coordination between technical staff, service providers, residents on duty, section in-charge, quality management team, and administrative staff of the institute.

\section{Cooperation of the Hospital/Indoor Patient Department (IPD) Staff}

Clinical staff posted in the wards is also instrumental in deliverance of quality services by the laboratory staff. Beginning from the training regarding proper and safe sample collection techniques, timely and appropriate sample transport, complete and accurate filling of requisition form to clinical correlation of the results, their cooperation helps in smooth and organized functioning of the clinical laboratory. Now as a routine, a roster is prepared for all the residents and technicians of Biochemistry department to distribute and cover all the wards to impart training to staff on duty regarding "good sampling techniques" every 6 months. They are also contacted from time to time to obtain their suggestions and feedback about the quality of services provided by the laboratory. In addition, periodic meetings with the clinical faculty are held to discuss their views about improvements/appropriateness of different aspects of clinical laboratory per their requirement. It is a daunting task to communicate with the staff posted in each and every ward, who may or may not be willing to cooperate, at our own level and requires great manpower, resources, and aid from administration.

\section{Central Store}

This is another area that needs to be brought into the loop for ascertaining the quality of supply received. The staff posted there are efficient and know their job well, but to maintain record and documentation as per NABL standard, they need to be instructed and trained. Their cooperation is also solicited for smooth and proper execution of this section of the laboratory.

\section{Conclusion}

In general, these are the major areas that may pose some difficulty in getting a laboratory accredited in government setup, although the actual scenario varies from institute to institute. Quality control, biomedical waste management, disaster management, proper and stringent documentation as per management, and technical clauses of NABL 112 are basic prerequisites to get a clinical laboratory 
accredited by $\mathrm{NABL}$, but the ultimate outcome is the amalgam of co-ordination and cooperation of the laboratory staff with the clinical staff and the administration. This article has been written with the intent to provide some insiders' insight about the task ahead to the laboratories in government organizations willing to participate for $\mathrm{NABL}$ accreditation and should not demoralize or prove to be a deterrent by any means for their efforts.

\section{References}

1. Chital NK, Bhat VG, Chavan PD, et al. The road to laboratory accreditation: experience of a tertiary care oncology center. Indian J Cancer 2016;53(1):204-205. DOI: 10.4103/0019-509X.180858.
2. Kanagasabapathy AS, Rao P. Laboratory accreditation-Procedural guidelines. Indian J Clin Biochem 2005;20(2):186-188. DOI: 10.1007/ BF02867425.

3. Maurya MR, Maurya B. Current scenario and distribution of NABL Accreditated laboratories in INDIA. J Pharmacol Clin Res 2017;3(5):555625. DOI: 10.19080/JPCR.2017.03.555625.

4. Wadhwa V, Rai S, Thukral T, et al. Laboratory quality management system: road to accreditation and Beyond. Indian J Med Microbiol 2012;30(2):131-140. DOI: 10.4103/0255-0857.96647.

5. Sinha M, Saini S, Gupta P, et al. Current status and way forward for national accreditation board for Testing and Calibration Laboratories Accreditation of Laboratories in Government Organizations. Indian J Pathol Microbiol 2018;61(3):461-463. DOI: 10.4103/IJPM.IJPM_630_17. 